\title{
OBITUARIES
}

\section{Dr. D. L. Hammick}

Dalziex Lleweliyn Hammick, emeritus fellow of Oriel College, Oxford, died at Oxford on October 17 in his eightieth year. He was one of the great teachers of chemistry of his generation.

Hammick was educated at Whitgift School, Croydon, and Magdalen College, Oxford, obtaining a first-class honours degree in chemistry in 1909 at the age of 22 . A year later, after a period in Munich, he married and took a post at Gresham's School, Holt, as chemistry master. There and later at Winchester, where he went in 1918, he showed his remarkable gifts as a teacher, and helped to transform the teaching of science in both schools. Organic chemistry he particularly loved. For him it was a garden full of interesting and beautiful flowers and he was able to communicate to all he taught its wonder and beauty, its high interest and, indeed, its fun. In 1921 he passed from schoolmastering to Oxford, as in an earlier generation Brereton Baker had done (Oxford could benefit by more of this), becoming fellow and tutor of Oriel College and tutor at Corpus Christi College. In 1952 he retired from Oriel and became an emeritus fellow, but he continued with his research work. He took the degree of D.Sc. in 1949 and was elected to fellowship of the Royal Society in 1952.

The Oxford system, started in the twenties, by which an undergraduate can get a class in honours in chemistry by spending only his last year carrying out research under guidance, suited Hammick very well. Over the years with his pupils at Oriel and Corpus he published many joint papers in the Journal of the Chemical Society and elsewhere. Some of the work was preparative work in aromatic chemistry; much of it was on the application of physical methods to the reactions of such compounds; at the beginning it was mainly on physical-chemical themes. From latent heats, compressibilities, transition temperatures and rates of reaction Hammick became interested in dipole moments, co-ordinate links, parachors and electron transfer in organic compounds. He and his pupils took part in the early work on bivalent carbon, the isocyanide link and also substitution in the benzene nucleus, which resulted in the "Hammick-Illingworth rule". Later on they studied the decarboxylation of compounds like picolinic and quinaldinic acids and thus the "Hammick equation" was devised. In this and much else on heterocyclic compounds Hammick showed himself original in his experimental technique and ingenious in accountirg for the results he obtained.

Although never loud voiced or a slapper of backs, Hammick in his own way was an enthusiast. He was invariably cheerful-a great gift in a research worker. Out of doors he enjoyed the countryside and he was a keen fisherman, and never happier, if he had to be away from work, than when he was fishing some stream in the cold and wet. In later life he walked slowly. He ascribed his pace to gout.

He kept his affection for the schools that fed Oxford. Although firm in asserting that examining schoolboys was a "wicked waste of time" he enjoyed examining for the entrance scholarships of the Oxford colleges. From 1922 until he was 78 he acted as awarder or examiner in chemistry at "A" or Scholarship level for the Schools of the Oxford and Cambridge Board, a necessary but very arduous job, too often neglected by the elect.

Last year an unfortunate car accident shocked him greatly and laid him low for many weeks. He was recovering from its effects and becoming once more his old self when he died.
In 1910 he married Phillippa Tilbrook, who survives him. They had two daughters and a son.

\section{A. S. Russelt}

\section{Academician V. I. Veksler}

Academician Vladimir Iosiftch Vekster was born on March 4, 1907, and died on September 22, 1966, at the age of 59 . He is best remembered for his discovery of the principle of phase stability of charged particles subject to acceleration by high frequency electromagnetic fields and his proposals for using this in the design of new types of particle accelerator.

Dr. Veksler graduated in 1931 from the Moscow Institute of Energetics. He was at the All-Union Electrotechnical Institute from 1930 until 1936, after which he worked at the Lebedev Institute of Physics of the U.S.S.R. Academy of Sciences, Moscow. In 1956 he was appointed director of the "Synchrophasotron" at the Joint Institute of Nuclear Research at Dubna, near Moscow. Veksler became a corresponding member of the U.S.S.R. Academy of Sciences in 1946 and in 1958 an Academician. In 1963 he was awarded the American Atoms for Peace Prize. He was a frequent delegate to international conferences on high energy accelerators and nuclear physics, and represented his country at several I.C.P.U.A.E. conferences. He was also a member of the editorial board of Atomnaya Energiya.

Veksler's early research included work on X-rays, nuclear physics, cosmic radiation and developments in GeigerMüller and proportional counters. He also studied electron-nuclear showers in cosmic rays. His classical papers on the principle of phase stability were published in 1944 , and from that time he devoted himself to the field of particle accelerators. Veksler's proposals initiated the post-war growth of a new family of particle accelerators. The essential feature of this principle consists of abandoning the previously accepted requirements of having exact resonance (synchronism) between the particle revolution frequency and the frequency of the accelerating field in cyclic accelerators. Thus charged particles can be accelorated in phase stable bunches making slow oscillations about a reference particle. In his celebrated papers, Veksler showed that this principle could be applied to a variety of different types of particle accelerator such as the synchro cyclotron, electron and proton synchrotrons and the microtron. Soon after Veksler published his papers, E. M. McMillan, of the University of California, quite independently arrived at the same conclusions and his name is invariably coupled with that of Veksler.

Convincing proof of the correctness of their proposals was soon provided. In England, Goward and Barnes converted a small betatron to synchrotron operation and raised the electron energy from $4 \mathrm{MeV}$ to $8 \mathrm{MeV}$. In America an existing cyclotron was converted to a synchro cyclotron and later the large Berkeley cyclotron, then under construction, was modified to a synchro cyclotron and attained proton energies of $350 \mathrm{MeV}$. In Russia. Veksler speedily constructed a $270 \mathrm{MeV}$ electron synchrotron at the Lebeder Institute, Moscow. This was the first of the large electron synchrotrons to operate, and still supports active research at the Lebedev Institute. Many synchro cyclotrons and electron synchrotrons came into operation in quick succession in the late forties.

Following close behind this wave of accelerator construction several large "constant-gradient" proton synchrotrons were begun. Of these, the largest is the Dubna "Synchrophasotron", which accelerates protons to $10 \mathrm{GeV}$ using a magnet of 36,000 tons. This is the machine which Veksler designed and latterly directed. It came into operation in 1957.

Dr. Veksler was a popular figure at international accelerator conferences and will be sadly missed by his colleagues.
W. WaLKINSHaW 